\title{
In the ghetto
}

\author{
David Cohen
}

THE Society for Psychical Research was set up in 1882 by eminent Victorian scientists who believed that, with the proper attention and the right instruments, there would be scientific answers to the ultimate questions. Does telepathy exist? Can mind move matter? Are there ghosts? And, the most profound of mysteries, do we survive after death? The Victorians were confident that, with the correct methods, such questions could be resolved. The Society was then more evangelical than it is now and, by 1891 , it had to warn members against complacency. A circular reminded them to continue to log all apparitions and manifestations; not everyone, it seems, was convinced by the evidence for life after death.

Throughout its one hundred years, the Society has attracted many distinguished scientists. Early presidents included the physicist Sir William Crookes, the psychologist William James, and Henri Bergson. I suspect that many of these founding fathers - women played no part as investigators but were, of course, often investigated as mediums - would be bitterly disappointed to learn that a century later there are still no definite answers and still no certitudes. Controversy reigns yet.

Ivor Grattan-Guinness has assembled a rather bitty book to celebrate the centenary of the Society. There are 34 chapters written by 27 different authors - assuming that the chapters written by "Brian Nisbet" and "the late Brian Nisbet" are both the product of the same earthbound pen. If not, I think we should be told how the manuscript got through.

Certainly, the book leaves little out from astrology to ufology. There are chapters on telepathy, metal bending, psychic healing, ghosts, teaching psychic research and much else besides. In theory, this should make a comprehensive, authoritative guide; in practice, however, it does not. With so many different authors, there is no unifying perspective. Each contributor is an enthusiast for his, or her, brand of psychic experience. We learn little about how various fields of psychic research relate; for instance, if there is such a phenomenon as telepathy, does that imply anything about ghosts?

Nevertheless, there are good chapters. Hans Bender gives a lucid account of the state of the poltergeist. He has impressive evidence from the Rosenheim case where many sober German engineers measured strange forces in a house where bulbs exploded "spontaneously" and things did go bump - day and night. Susan Black-
Psychical Research: A Guide to its History, Principles and Practices. Edited by Ivor Grattan-Guinness. Pp.424. ISBN 0-85030-316-8. (Aquarian Press, Northamptonshire: 1982.) £7.95, \$14.95.

more writes interestingly about out-of-thebody experiences and argues that we should link them to our less-aerial imaginative experiences. Many contributions, however, are patchy, such as those on telepathy and clairvoyance and on survival after death. This is particularly disappointing because the latter subject keeps cropping up as a key idea.

Wide-ranging though it seems to be, the book fails to ask some important questions. Why, for example, are people so interested in the paranormal? To a sceptic like myself, it seems that a powerful motive for doing psychic research is to prove that there is an after-life and that you, the researcher, will get to enjoy it. There is also little attempt to weigh up the evidence selectively and to suggest that, perhaps, the evidence for some paranormal claims is much stronger than for others.

The other great weakness is that the book barely explores the relationship between parascience and mainstream science. Most paranormal research is reported in journals devoted exclusively to the subject. It all remains outside "normal" science. That is due partly, of course, to the dogmas of "normal" science which often regards such weird wonders necessarily as nonsense. But to create a ghetto for parascience is not healthy. It allows its practitioners to get away with much poor thinking and methodology, and it also allows normal science to evade the challenge posed by impressive evidence such as that in the Rosenheim case and in some telepathy results. This book is an affectionate tribute to a worthy Society but is not the authority it aspires to be.

David Cohen is Editor of Psychology News.

\section{Turning over puzzles in the mind}

\section{Stuart Sutherland}

Mental Images and their Transformations.

By Roger N. Shepard and Lynn A. Cooper. Pp.364. ISBN 0-262-19200-4. (MIT Press/ Bradford: 1982.) \$25, £20.

REVERTING to an earlier tradition, psychologists are becoming increasingly preoccupied with the mind. They are even using introspection as a source of ideas about mental activity, but unlike their predecessors who worked in the early years of this century they feel that before being made public the results of introspection must acquire the dignity that only experiments can lend.

Professor Shepard is one of the most cunning masters of this technique. In 1971 he reported an experiment in which subjects were shown pairs of shapes of the kind displayed in Fig. 1 (see p.354). The members of each pair were either identical or were mirror images of one another. The two shapes were shown at different orientations, one being rotated with respect to the other through an angle that varied from 0 to 180 degrees. The task was to decide whether the two shapes were identical. Shepard found that the time taken to reach a decision increased linearly with the angular difference in orientation between the members of the pair being viewed and that the increase was the same whether one shape was rotated with respect to the other in the frontal parallel plane or around a vertical axis, that is to say, rotated in depth.

Shepard concluded that visual images can be rotated in the head and that it takes a constant time to rotate an image through a constant angle. $\mathrm{He}$ and his colleagues corroborated this result in a series of ingenious experiments. They found, for example, that if subjects were told to rotate a given shape in advance through a particular angle and were then presented with a test shape, the time taken to decide whether it was the same as the original shape was determined by the difference in the orientation of the test shape and the orientation to which the subjects had mentally rotated the original. Shepard was also able to demonstrate that when a shape is being mentally rotated through a given angle, the image passes through the intermediate orientations. Of course his subjects could - and did - tell him how they were performing the task, but it required experiments to show that the rate of rotation was constant per unit angle.

Mental Images and Their Transformations, written in collaboration with $\mathrm{Dr}$ Cooper, contains little that is new. Most of 